\title{
A tribute to Professor Adam Boratyński: an eminent Polish botanist and scholar
}

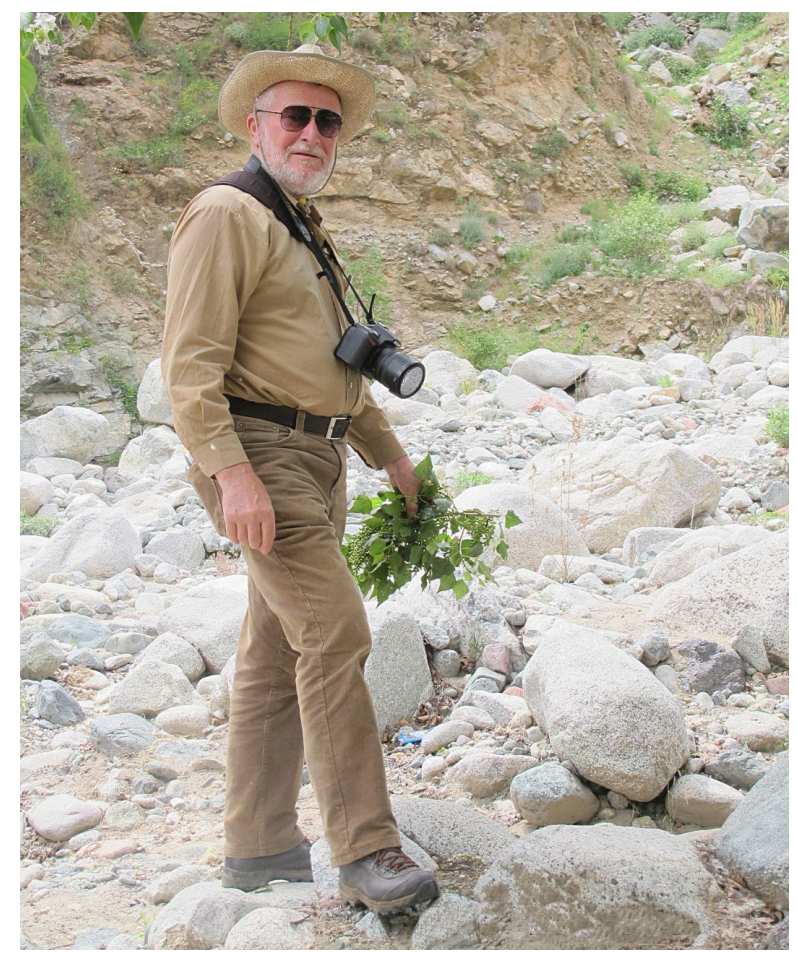

Adam Boratyński, expedition to Morocco (2014). Photo: archives of the expedition team

This issue of Plant and Fungal Systematics includes nine papers dedicated to Professor Adam Boratyński that reflect his scientific interests. Professor Adam Boratyński is a broadly recognized scientist and a distinguished professor. His contributions to dendrology span multiple fields of inquiry, including biology, ecology, evolution, and biogeography, especially from Mediterranean areas of Europe, Asia, and Africa. Professor Boratyński was born on September 24, 1948 in Syców (Lower Silesia), Poland. In 1972, he graduated from the Poznan University of Life Sciences, where he completed his PhD in 1979, and earned habilitation in 1992. His doctoral thesis dealt with the distribution and variability of Acer pseudoplatanus in Poland. Since 1972, Professor Boratyński has continued his research and teaching at the Institute of Dendrology, Polish Academy of Sciences in Kórnik (as a professor since 2002). For most of his career, he has been an active and influential member of numerous scientific entities, such as the Polish Botanical Society, the Polish Forestry Society, the Committee for Nature Conservation of the Polish Academy of Sciences. Beyond being an author on numerous scientific and popular science articles and books, he was also a member of the editorial staff of the important monographic series 'Nasze drzewa leśne' ['Our forest trees']. We have taken the initiative to dedicate this special issue to recognize Professor Boratyński's significant contributions to the evolutionary biology and ecology of the dendroflora. The editors thank the authors and collaborators for their contributions to this issue highlighting the career of this renowned Polish botanist.

\section{Elżbieta Cieślak}

W. Szafer Institute of Botany, Polish Academy of Sciences, Kraków, Poland

Marlena Lembicz

Faculty of Biology Adam Mickiewicz University,

Poznań, Poland

Monika Dering

Department of Silviculture Poznań University of Life Sciences, Poznań, Poland

Adam Flakus

W. Szafer Institute of Botany, Polish Academy of Sciences, Kraków, Poland

Jolanta Miadlikowska

Department of Biology, Duke University,

Durham NC, USA 